\title{
Treatment of chronic respiratory failure in kyphoscoliosis: oxygen or ventilation?
}

\author{
B. Buyse, W. Meersseman, M. Demedts
}

Treatment of chronic respiratory failure in kyphoscoliosis: oxygen or ventilation? B. Buyse, W. Meersseman, M. Demedts. C) ERS Journals Ltd 2003.

ABSTRACT: Patients with kyphoscoliosis and chronic respiratory insufficiency are treated either with home oxygen therapy or ventilation. Kyphoscoliotic patients demonstrate impaired ventilatory mechanics, consequently ventilation seems to be the treatment of choice. Yet, no randomised controlled trials (CRT) exist to prove it.

Most investigators find it difficult to ethically justify a CRT. Therefore, the current authors performed the following retrospective study: survival and pulmonary function were analysed in all consecutive kyphoscoliotic patients who started long-term oxygen therapy (LTO group; $n=15$, aged $62 \pm 11$ yrs (mean \pm SD)) or LTO plus nocturnal nasal intermittent positive pressure ventilation (nNIPPV group; $n=18$, aged $61 \pm 7 \mathrm{yrs}$ ) in the Dept of Pulmonology (University Hospital Gasthuisberg, Leuven) between 1990-2002.

Prior to treatment partial pressure of oxygen $\left(\mathrm{PO}_{2}\right)$ was lower, partial pressure of carbon dioxide $\left(\mathrm{PCO}_{2}\right)$ tended to be higher and vital capacity (VC) tended to be lower in the nNIPPV group than in the LTO group $\left(\mathrm{PO}_{2} 5.9 \pm 1\right.$ versus $6.7 \pm 0.9 \mathrm{kPa}(44 \pm 8$ versus $50 \pm 7 \mathrm{mmHg}), \mathrm{PCO}_{2} 8 \pm 1$ versus $7.3 \pm 0.9 \mathrm{kPa}(60 \pm 8$ versus $55 \pm 7 \mathrm{mmHg})$, VC $32 \pm 12$ versus $40 \pm 16 \%$ predicted, or $645 \pm 244$ versus $970 \pm 387 \mathrm{~mL}$ ). In the nNIPPV group the 1 -yr survival was higher $(100 \%$ versus $66 \%)$. nNIPPV patients demonstrated an improvement in $\mathrm{PO}_{2}$ (breathing air) $+54 \%, \mathrm{PCO}_{2}$ (breathing air) $-21 \%, \mathrm{VC}+47 \%$ and maximal static inspiratory mouth pressure $+33 \%$; these improvements were absent in the LTO group.

In conclusion, nocturnal nasal intermittent positive pressure ventilation, plus longterm oxygen therapy results in more favourable survival and changes in blood gases and respiratory function than long-term oxygen therapy alone.

Eur Respir J 2003; 22: 525-528.
Dept of Pulmonology, University Hospital Gasthuisberg Leuven, Katholieke Universiteit Leuven, Leuven, Belgium.

Correspondence: B. Buyse

Dept of Pulmonology

University Hospital Gasthuisberg

Herestraat 49

B-3000 Leuven

Belgium

Fax: 3216346803

E-mail: Bertien.Buyse@uz.kuleuven.ac.be

Keywords: Chronic respiratory insufficiency home respiratory care

kyphoscoliosis

mechanical ventilation

oxygen therapy

Received: August 162002

Accepted after revision: March 252003
When kyphoscoliosis is complicated by cardiorespiratory failure, the prognosis is grim [1]. However, improved survival is possible with appropriate treatment. In kyphoscoliotic patients ventilatory mechanics are impaired and may cause considerable hypoventilation, especially during sleep [2-4]. Taking this into consideration nocturnal ventilation seems to be the treatment of choice. Different groups have demonstrated that the long-term outcome of home nocturnal nasal intermittent positive pressure ventilation (nNIPPV) is good in these patients $[5,6]$. Nonetheless, nowadays, the majority of these patients are still treated with long-term oxygen therapy (LTO) [7, 8]. In a French Antadir analysis published in 1996 [8], $69 \%$ of 662 patients with kyphoscoliosis were treated with LTO alone and only $31 \%$ with ventilation. Survival of patients with kyphoscoliosis treated by ventilation was better: their risk of death (taking age, sex, body mass index, partial pressure of oxygen $\left(\mathrm{PO}_{2}\right)$, partial pressure of carbon dioxide $\left(\mathrm{PCO}_{2}\right)$, forced expiratory volume in one second (FEV1), vital capacity (VC) and FEV1/VC into account) was $40 \%$ of that of those treated initially with LTO alone. To the best of the authors' knowledge, this publication [8] is the only study comparing the influence of different types of treatment (home ventilation versus LTO) on the survival of patients with kyphoscoliosis. Yet, the reason for better survival was not studied. Therefore, the current authors thought it would be worthwhile to add an analysis of not only survival but also evolution of arterial blood gases and spirometric values of patients with severe kyphoscoliosis receiving LTO and/or
nNIPPV to determine which of the therapeutical methods is superior and what the explanations are for this.

\section{Material and methods}

\section{Patients}

In March 2002 a retrospective analysis was performed of all consecutive patients with kyphoscoliosis and respiratory insufficiency who started LTO and/or nNIPPV in the Dept of Pulmonology (University Hospital Gasthuisberg, Leuven).

The first study group consisted of all patients who started LTO between September 1990 and March 2001: 15 patients (the LTO group). Since 1995 one of the pulmonologists was accustomed to noninvasive ventilation treatment: all 18 consecutive patients with kyphoscoliosis and chronic respiratory insufficiency who presented at their unit between March 1995 and March 2001 were treated with nNIPPV plus LTO and were included as the second study population (the nNIPPV group).

\section{Oxygen and nocturnal nasal intermittent positive pressure ventilation equipment}

In the LTO group, oxygen was prescribed for at least $15 \mathrm{~h} \cdot \mathrm{day}^{-1}$ at a rate of $1-3 \mathrm{~L} \cdot \mathrm{min}^{-1}$ depending on blood gas values (the current authors pursued a $\mathrm{PO}_{2}>8 \mathrm{kPa}(>60 \mathrm{mmHg})$ ). 
In the nNIPPV group, oxygen supplement during the day was prescribed in the same way as in the LTO group. Nasal ventilation (using either a volume-cycled (Eole 3; Saime, SavignyLe-Temple, France) or a pressure-cycled ventilator ( $\mathrm{O}^{\prime}$ nyx; Nellcor Puritan Bennet, Villers-les-Nancy, France)) was started under supervision of a pulmonologist. Oxygen supplement on the ventilator $\left(1-4 \mathrm{~L} \cdot \mathrm{min}^{-1}\right)$ was installed. The current authors pursued a nocturnal oxygen saturation $>90 \%$ and an acute decrease in daytime $\mathrm{PCO}_{2}$ of $\geqslant 0.7 \mathrm{kPa}(5 \mathrm{mmHg})$.

\section{Pulmonary function measurements}

Measurements of pulmonary function included VC and FEV1. The predicted values of the European Respiratory Society were used [9]. Normally arm span is used as a surrogate for true height in severe kyphoscoliotic patients. Yet, in this retrospective study, data on arm span were lacking in several patients; therefore, the "measured height" was used. Arterial blood gases were also measured (in sitting position, breathing air).

In the second group (the nNIPPV group) maximal static inspiratory (MIP) and expiratory mouth pressures were measured according to technique of ROCHESTER and ARORA [10] and their prediction equations were also applied.

\section{Statistical analysis}

Means \pm SD were calculated. Comparisons between groups were made using the Mann-Whitney U-test. Correlation test was performed using the Spearman test. A p-value $<0.05$ was considered as significant. Survival analysis was estimated using the Kaplan-Meier method from the first day of home treatment; March 31, 2002, is taken as the closing date, which thus gives a follow-up period of $\geqslant 1$ to $>11 \mathrm{yrs}$.

\section{Results}

\section{Patient characteristics at baseline}

All patients were admitted to the hospital for complaints of dyspnoea and limb oedema compatible with right heart failure with or without accompanying acute bronchitis. They received appropriate treatment with diuretics, corticosteroids, bronchodilators, antibiotics, mucolytics and oxygen. After $\geqslant 1$ week of in-hospital treatment they performed baseline respiratory function measurements (table 1) and as these data were compatible with respiratory insufficiency home LTO was prescribed. The patients hospitalised in the department of the pulmonologist accustomed to noninvasive ventilation started nNIPPV in addition to LTO. All patients coped with longterm nNIPPV-treatment.

The LTO group consisted of five males and 10 females with a mean age of $62 \pm 11 \mathrm{yrs}$. The nNIPPV group consisted of four males and 14 females with a similar mean age of $61 \pm 7 \mathrm{yrs}$. The majority of patients had the idiopathic form of kyphoscoliosis, two patients out of each group had the post-polio form and one patient out of the LTO group had the combination of kyphoscoliosis and achondroplasia. There was no significant difference between both groups considering the presence of major comorbidities, such as ischaemic heart disease, cardiac arrhythmia's, hypertension, obesity or diabetes.

As demonstrated in table 1 all patients had daytime respiratory failure and had markedly reduced lung volumes; inspiratory muscle strength was also well below predicted. Patients who started nNIPPV demonstrated a significant lower baseline $P_{2}$, tended to have a higher baseline $P \mathrm{PO}_{2}$ as well as a lower VC than the patients who started LTO therapy alone (table 1). The Tiffeneau-index was identical for both groups.

\section{Probability to continue treatment (estimate of survival)}

In the present study population the probability to continue treatment was a good estimate of survival as death was the principal cause of withdrawal (the exception was one LTO patient who developed carbonarcosis after 77 months and now uses tracheal positive pressure ventilation).

As demonstrated in figure 1 the survival curve of the LTO group was significantly lower than the survival curve of the nNIPPV group $(p<0.05)$. The difference was already obvious during the first follow-up year: after $1 \mathrm{yr}$ of treatment survival was only $66 \%$ in the LTO-group versus $100 \%$ in the nNIPPV group.

Table 1.-Pulmonary function and daytime blood gases (breathing air) prior to treatment (baseline) and when on treatment during at least 6 months (end)

\begin{tabular}{|c|c|c|c|c|c|c|c|c|c|c|c|c|c|c|}
\hline & & LT & $\mathrm{O}$ group ${ }^{\#}$ & & & & & $\mathrm{aNI}$ & PPV group & & & $\begin{array}{r}\text { Differe } \\
\text { LTO a } \\
\text { grou }\end{array}$ & $\begin{array}{l}\text { ace be } \\
\text { d nN } \\
p \text {-va }\end{array}$ & $\begin{array}{l}\text { tween } \\
\text { IPPV } \\
\text { lues }\end{array}$ \\
\hline & Baseline & & End & & $\Delta^{\S}$ & & Baseline & & End & & $\Delta^{\S}$ & Baseline & End & $\Delta^{\S}$ \\
\hline $\mathrm{n}$ & mean $\pm \mathrm{SD}$ & $\mathrm{n}$ & mean $\pm \mathrm{SD}$ & $\mathrm{n}$ & mean \pm SD & $\mathrm{n}$ & mean $\pm \mathrm{SD}$ & $\mathrm{n}$ & mean $\pm \mathrm{SD}$ & $\mathrm{n}$ & mean $\pm \mathrm{SD}$ & & & \\
\hline 15 & $62 \pm 7$ & & & & & 18 & $61 \pm 7$ & & & & & NS & & \\
\hline 15 & $153 \pm 14$ & & & & & 18 & $145 \pm 11$ & & & & & NS & & \\
\hline 15 & $78 \pm 18$ & & & & & 18 & $82 \pm 12$ & & & & & NS & & \\
\hline 15 & $50 \pm 7$ & $11^{+}$ & $56 \pm 9$ & $11^{+}$ & $13 \pm 13$ & 18 & $44 \pm 8$ & 18 & $66 \pm 10$ & 18 & $54 \pm 34$ & $<0.05$ & 0.01 & 0.001 \\
\hline 15 & $55 \pm 7$ & $11^{+}$ & $52 \pm 5$ & $11^{+}$ & $0 \pm 6$ & 18 & $60 \pm 8$ & 18 & $47 \pm 8$ & 18 & $-21 \pm 11$ & NS & 0.01 & 0.0001 \\
\hline 15 & $40 \pm 16$ & $9^{+}$ & $46 \pm 16$ & $9^{+}$ & $6 \pm 23$ & 18 & $32 \pm 12$ & 18 & $44 \pm 10$ & 18 & $47 \pm 44$ & NS & NS & $<0.01$ \\
\hline 15 & $970 \pm 387$ & $9^{+}$ & $1064 \pm 452$ & $9^{+}$ & $4 \pm 24$ & 18 & $645 \pm 244$ & 18 & $830 \pm 292$ & 18 & $51 \pm 53$ & $<0.01$ & NS & $<0.01$ \\
\hline NA & & & & & & 12 & $44 \pm 13$ & 12 & $57 \pm 17$ & 12 & $33 \pm 30$ & & & \\
\hline NA & & & & & & 12 & $3.7 \pm 1.1$ & 12 & $4.8 \pm 1.2$ & 12 & $34 \pm 31$ & & & \\
\hline
\end{tabular}

LTO: long-term oxygen therapy at home; nNIPPV: nocturnal nasal intermittent positive pressure ventilation at home; FEV1: forced expiratory volume in one second; VC: vital capacity; $\mathrm{PO}_{2}$ : partial pressure of oxygen; $\mathrm{PCO}_{2}$ : partial pressure of carbon dioxide; MIP: maximal inspiratory muscle force; NA: not available; ns: nonsignificant; ${ }^{*}$ : LTO group (10 males and five females); ${ }^{\text {: }}$ nNIPPV group (14 males and four females); ${ }^{+}$: four patients died before re-evaluation was possible and in two remaining patients a spirometric measurement was not possible; ${ }^{\text {: }}$ (value before treatment-value after start of treatment)/value before treatment; Conversion factor $\mathrm{mmHg}$ to $\mathrm{kPa} \times 0.133$. 


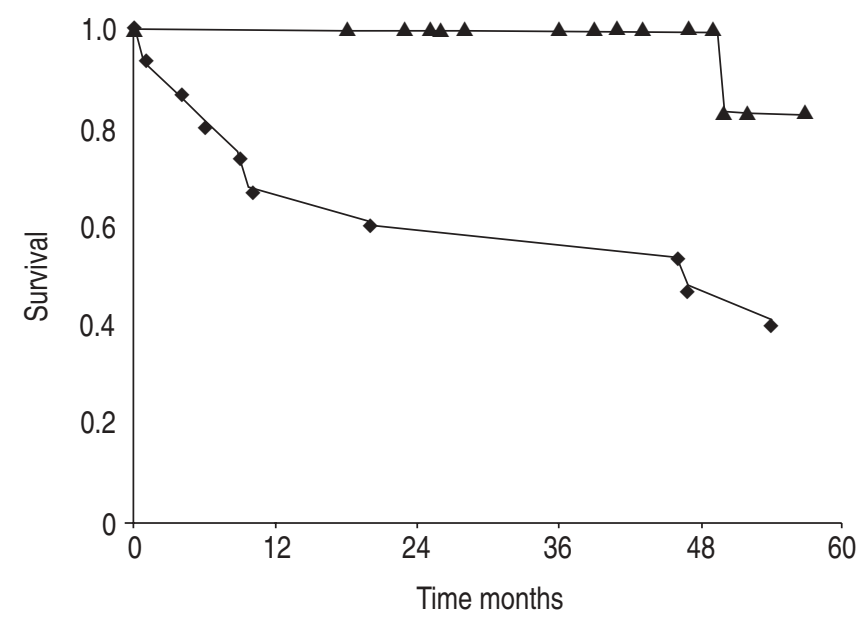

Fig. 1. - Survival curves of kyphoscoliotic patients treated with longterm oxygen therapy at home (LTO) or LTO and nocturnal nasal intermittent positive pressure ventilation at home (nNIPPV). $\diamond$ : LTO group; $\boldsymbol{\Lambda}$ : nNIPPV group.

\section{Evolution of daytime blood gases and pulmonary function}

In the LTO group re-evaluation was performed after $10 \pm 4$, range 6-18 months. Re-evaluation of $\mathrm{PO}_{2}$ and $\mathrm{PCO}_{2}$ was possible in 11 patients (four patients died before); in these patients there tended to be a nonsignificant increase in $\mathrm{PO}_{2}$ (breathing room air) from $6.7 \pm 1$ to $7.4 \pm 1.2 \mathrm{kPa}(50 \pm 8$ to $56 \pm 9 \mathrm{mmHg}$ ) without significant change in $\mathrm{PCO}_{2} 7 \pm 0.8$ to $6.9 \pm 0.7 \mathrm{kPa}(53 \pm 6$ to $52 \pm 5 \mathrm{mmHg})$. VC before and after LTO treatment could only be compared in nine patients (as four patients died before re-evaluation and two patients were disabled to such a degree that a spirometry was impossible). There was no change in VC: the value was $45 \pm 17$ before and $46 \pm 16 \%$ predicted after start of treatment, which represents a negligible increase of $33 \pm 276 \mathrm{~mL}$.

In the nNIPPV group re-evaluation was performed after a same treatment period: $10 \pm 3$, range $7-16$ months. As demonstrated in table 1 the change in $\mathrm{PO}_{2}$ and $\mathrm{PCO}_{2}$ was significantly larger in the nNIPPV group than in the LTO group: the $\mathrm{PO}_{2}$ (breathing room air) increased from $5.9 \pm 1$ to $8.8 \pm 1.3 \mathrm{kPa}(44 \pm 8$ to $66 \pm 10 \mathrm{mmHg})(\mathrm{p}<0.0001)$ and $P_{\mathrm{CO}_{2}}$ decreased from $8 \pm 1$ to $6.3 \pm 1 \mathrm{kPa}(60 \pm 8$ to $47 \pm 8 \mathrm{mmHg})$ $(\mathrm{p}<0.0001)$. Although the nNIPPV patients demonstrated a significantly lower baseline $\mathrm{PO}_{2}$ and tended to have a higher baseline $\mathrm{PCO}_{2}$ than the LTO-patients, end-values (after start of treatment) of $\mathrm{PO}_{2}$ were significantly higher in the nNIPPV group (table 1). VC increased from $32 \pm 12$ to $44 \pm 10 \%$ pred (table $1, \mathrm{p}<0.005$ ) which represents an increase of $238 \pm$ $183 \mathrm{~mL}$; yet, VC still tended to be lower than the end-VC in the LTO-group ( $44 \pm 10$ versus $46 \pm 16 \%$ pred or $830 \pm 292$ versus $1064 \pm 452 \mathrm{~mL}$, NS). MIP was measured in 12 patients of the nNIPPV group: MIP increased from $44 \pm 13$ to $57 \pm 17$ $\%$ pred $(\mathrm{p}=0.05)$ or from $3.7 \pm 1.1 \mathrm{kPa}$ to $4.8 \mathrm{kPa}(\mathrm{p}<0.05)$ (table 1). As demonstrated in figure 2 there was a significant correlation between the \% increase in MIP and the \%increase in $\mathrm{VC}(\mathrm{p}<0.05)$.

\section{Discussion}

The aim of the present study was to compare survival and pulmonary function in kyphoscoliotic patients who started LTO (LTO group) versus kyphoscoliotic patients who started LTO plus nocturnal nasal ventilation (nNIPPV group) to determine which of both therapeutical methods is superior and what the explanations are for this.

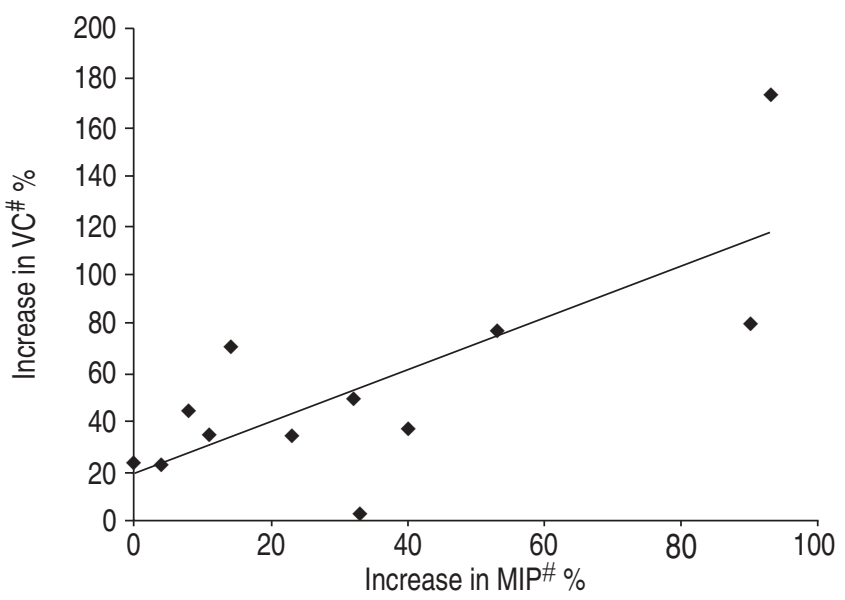

Fig. 2.-Correlation between the increase in vital capacity (VC) and the increase in maximal inspiratory mouth pressure (MIP) in patients on nocturnal nasal intermittent positive pressure ventilation and longterm oxygen therapy at home. " : (value before treatment-value after treatment)/value before treatment.

Nowadays, a lot of kyphoscoliotic patients with chronic respiratory insufficiency are still treated with LTO alone (without home ventilation), even in the current authors' department. The present authors are aware of the fact that several readers of this article will not understand why LTO alone is still proposed to kyphoscoliotic patients with inherent impaired ventilatory mechanics and hypoventilation. Yet, even nowadays, a lot of pulmonologists lack experience with the "new" strategy nNIPPV and/or presume that their kyphoscoliotic, often older, patients will not cope with this "embarrassing" therapy. Moreover, no randomised trial exists demonstrating the benefit of nNIPPV in kyphoscoliosis; while there are several well-known randomised trials clearly showing the benefit of LTO (in chronic obstructive pulmonary disease) $[11,12]$.

In March 2002 the current authors decided to perform a retrospective analysis of survival and pulmonary function in all kyphoscoliotic patients with respiratory insufficiency treated in the Dept of Pulmonology (University Hospital Gasthuisberg, Leuven). The differences between patients treated by LTO alone and patients treated by the pulmonologist accustomed to noninvasive ventilation with nNIPPV+LTO were striking. Nowadays, it is unlikely there will ever be a large scale CRT on nNIPPV in kyphoscoliotic patients to inform practice, because of the rarity of the condition and more importantly, because such a study, according to several pulmonologists, would be difficult to justify ethically. Therefore, the present authors believe that the present retrospective study is as close as anyone is likely to get to a CRT.

Survival was better in the present group treated with nNIPPV+LTO than with LTO alone. The difference was already obvious after $1 \mathrm{yr}$ of treatment. Nevertheless, the present authors are cautious to completely attribute these positive survival data to the nNIPPV treatment alone.

This is only possible when both arms of the study are very similar study populations. In the present analysis both study groups could be considered as such. First, the degree of obstructive dysfunction measured by the Tiffeneau index was comparable in both arms of the study. Patients with kyphoscoliosis often additionally demonstrate a certain degree of obstructive disease. STRÖM et al. [7] demonstrated that the survival rate of patients with kyphoscoliosis was significantly higher in patients in whom hypoxia was caused by thoracic spine deformity than when caused by the combination of thoracic deformity and chronic lung or 
obstructive airways disease. Secondly, there was also no significant difference between both arms of the study considering the presence of major comorbidities. Thirdly, in a retrospective study including patients over a period of $>10$ yrs there may be some concern that treatments other than nNIPPV were different between the two study arms. Yet, both study groups were treated in the same Dept of Pulmonology with the same treatment practice considering drugs or secretion management for kyphoscoliotic patients; this treatment strategy did not change over the last $10 \mathrm{yrs}$. The current authors' therefore consider that the only important difference in treatment between both arms of the study was nNIPPV and possibly a closer supervision by an interested physician.

The time at which a treatment is initiated may also affect length of survival: the earlier in the evolution of a disease a treatment is started, the longer survival is likely to be. Yet, in the present analysis, there was no difference in mean age between both groups. Moreover, the degree of pulmonary restriction tended to be more pronounced at baseline and after treatment in the patients who started nNIPPV+LTO than in the patients who started LTO alone, indicating that severity of the pulmonary restriction was higher in the nNIPPV group, although their survival was better.

In the LTO group there was only a small and statistically nonsignificant increase of $\mathrm{PO}_{2}$ without change in $\mathrm{PCO}_{2}$. In the nNIPPV-group the increase in daytime $\mathrm{PO}_{2}$ was marked and accompanied by a decrease in $\mathrm{PCO}_{2}$. Amelioration in daytime blood gases is observed in many studies on nNIPPV. The hypotheses explaining this amelioration have recently been clearly summarised in a review article by TURKINGTON and ELLIOT [13]. Improvement could be the result of: 1) an increase in respiratory drive secondary to improved nocturnal blood gases and less sleep fragmentation; 2) resting of chronically fatigued respiratory muscles; or 3) changes in chest wall or lung compliance due to a "stretching action" resulting in a higher functional residual capacity, opening up low ventilation/perfusion lung units, thus decreasing shuntlike venous admixture. Yet, little is really proven in patients with kyphoscoliosis. The current authors only found five previous reports dealing with this topic $[6,14-17]$ before the present one. There are no reports on the evolution of respiratory drive parameters in patients with kyphoscoliosis. ELLIS et al. [14] demonstrated an increase in MIP in patients with kyphoscoliosis who started noninvasive ventilation, while GoLDSTEIN et al. [15] could only demonstrate an increase in inspiratory muscle endurance. In the present study population, nNIPPV+LTO was accompanied by a significant increase in MIP. To the best of the authors' knowledge the present study is the first to find a (small but) significant increase in VC after start of nNIPPV in kyphoscoliotic patients. All others [6, 14-17] found no change in VC which is, at least, curious. Indeed, there are reports mentioning that even only intermittent use (2-3 times a day for $5 \mathrm{~min}$ ) of positive pressure hyperinflation results in increased lung volumes in patients with restrictive chest wall disorder $[18,19]$. These authors mentioned that the increase was due to changes in chest wall or lung compliance. Compliance was not measured in the current study, consequently the present authors cannot speculate on this. Yet, MIP was measured. Apart from chest wall and lung compliance, inspiratory muscle force is the other determinant of $\mathrm{VC}$. The present study suggests that in kyphoscoliotic patients diminished inspiratory muscle force did play a role in the degree of loss in VC: the current study found that after nNIPPV increases in MIP were significantly correlated with increases in VC (fig. 2).

In conclusion, survival was better in kyphoscoliotic patients treated with nocturnal nasal intermittent positive pressure ventilation combined with long-term oxygen therapy than in kyphoscoliotic patients with an almost similar (even milder) degree of respiratory insufficiency treated with long-term oxygen therapy alone. Only the combination of nocturnal nasal intermittent positive pressure ventilation and long-term oxygen therapy resulted in a significant increase in daytime partial pressure of oxygen and a significant decrease in daytime partial pressure of carbon dioxide accompanied by significant increases in maximum inspiratory pressure and vital capacity.

\section{References}

1. Bergofsky EH, Turino GM, Fishman AP. Cardiorespiratory failure in kyphoscoliosis. Medicine: 1959: 263-317.

2. Mezon BL, West P, Israels J, Kryger M. Sleep breathing abnormalities in kyphoscoliosis. Am Rev Respir Dis 1980; 122: 617-621.

3. Guilleminault C, Kurland G, Winkle R, Miles LE. Severe kyphoscoliosis, breathing and sleep. Chest 1982; 79: 626630.

4. Sawicka EH, Branthwaite MA. Respiration during sleep in kyphoscoliosis. Thorax 1987; 42: 801-808.

5. Leger P, Bedicam JM, Cornette A, et al. Nasal intermittent positive pressure ventilation. Long-term follow-up in patients with severe chronic respiratory insufficiency. Chest 1994; 105: 100-105.

6. Simonds AK, Elliott MW. Outcome of domiciliary nasal intermittent positive pressure ventilation in restrictive and obstructive disorders. Thorax 1995; 50: 604-609.

7. Ström K, Pehrsson K, Boe J, Nachemson A. Survival of patients with severe thoracic spine deformities receiving domiciliary oxygen therapy. Chest 1992; 102: 164-168.

8. Chailleux E, Fauroux B, Binet F, Dautzenberg B, Polu JM. Predictors of survival in patients receiving domiciliary oxygen therapy or mechanical ventilation. Chest 1996; 109: 741-749.

9. ERS-Statement. Standardized lung function testing. Eur Respir J 1993; 6: Suppl. 16, 1-100.

10. Rochester DF, Arora NS. Respiratory muscle failure. Med Clin North Am 1983; 67: 573-597.

11. Medical Research Council Working Party. Long term domiciliary oxygen therapy in chronic hypoxic cor pulmonale complicating chronic bronchitis and emphysema. Lancet 1981; i: 684-686.

12. Nocturnal Oxygen Therapy Trial Group. Continuous or nocturnal oxygen therapy in hypoxemic chronic obstructive lung disease. A clinical trial. Ann Intern Med 1980; 93: 391398.

13. Turkington PM, Elliott MW. Rationale for the use of non-invasive ventilation in chronic ventilatory failure. Thorax 2000; 55: 417-423.

14. Ellis ER, Grunstein RR, Chan S, Bye PTP, Sullivan CE. Noninvasive ventilatory support during sleep improves respiratory failure in kyphoscoliosis. Chest 1988; 94: 811815.

15. Goldstein RS, De Rosie JA, Avendano MA, Dolmage TE. Influence of noninvasive positive pressure ventilation on inspiratory muscles. Chest 1991; 99: 408-415.

16. Bach JR, Robert D, Leger P, Langevin B. Sleep fragmentation in kyphoscoliotic individuals with alveolar hypoventilation treated by NIPPV. Chest 1995; 107: 1552-1558.

17. Schönhofer B, Köhler D. Effect of non-invasive mechanical ventilation on sleep and nocturnal ventilation in patients with chronic respiratory failure. Thorax 2000; 55: 308313 .

18. Sinha R, Bergofsky EH. Prolonged alteration of lung mechanics in kyphoscoliosis by positive pressure hyperventilation. Am Rev Respir Dis 1972; 106: 47-57.

19. Simonds AK, Parker RA, Branthwaite MA. The effect of intermittent positive-pressure hyperinflation in restrictive chest wall disease. Respiration 1989; 55: 136-143. 